\title{
LIFE-CYCLE COST ANALYSIS IN PAVEMENT MANAGEMENT SYSTEM
}

Pavement Management System (PMS) is a set of methods and tools which allow for optimal allocation of limited resources while keeping the road network in serviceable condition. The system evaluates the viability of all maintenance, rehabilitation and reconstruction (MR\&R) actions; the evaluation is a comparison process between procurement cost of $M R \& R$ action and benefits, which are achieved by the new, more favourable, serviceability conditions attained as a result of this particular action. The investment cost - procurement costs of $M R \& R$ action are evaluated in terms of economical effectiveness by means of Life-Cycle Cost Analysis (LCCA).

Keywords: Pavement management system, pavement evaluation, serviceability, structural analysis, user costs, cost benefit analysis.

\section{Introduction}

Within LCCA, different variants of MR\&R actions are assessed in terms of impact on condition of the pavement, i.e. structural distress and surface distress. Different variants of MR\&R actions have different impact on serviceability, and operational performance of treated road sections. In addition, each variant has different procurement costs, it influences directly maintenance costs of treated road section, and prolongs its service life by different amount. All these aspects come into consideration during the LCCA; in addition, the impact on road user costs, environmental costs, and accident costs are evaluated in detail [1]. Within the framework of LCCA, evaluation of economic efficiency is carried out with the use of Cost-Benefit Analysis (CBA), which evaluates the benefits yielded by improved operating parameters of particular road, in relation to procurement cost of applied MR\&R actions. The Payback Period (PP), Internal Rate of Return (IRR) and Net Present Value (NPV) are economic indicators of the Cost-Benefit Analysis (CBA).

Utilization of LCCA started in the 90's and is closely described in [2]. Basic economic parameters were defined, and based on deterministic models, prediction trend lines were created. This article complexly describes the role of LCCA in the PMS in the context of diagnostics, pavement evaluation and structural assessment of the pavement. The result of structural assessment is the calculation of residual service life based on trend lines for complex modulus of elasticity, design of overlay, algorithm for selection of repair technologies, and Cost-Benefit Analysis.

\section{Diagnostics and pavement evaluation}

Diagnostics and pavement evaluation are performed on the basis of pavement serviceability and pavement structure assessment.

\subsection{Road network inventory}

Main part of this module is a database gathering data on the road network. In addition to data on traffic volume and physical characteristics of road sections, as well as physical characteristics of other road network assets such as bridges and culverts, substantial part of the database consists of data regarding surface characteristics of pavements i.e., pavement distress data. The PMS distinguishes following types of pavement distresses: Roughness, Rut depth, Skid resistance, Surface distress.

These distresses can be measured locally with laboratory equipment; however, in practice, variety of survey instruments for data collection is used for quicker, continuous, and foremost, price efficient measurement. For these reasons, Slovak Road Administration holds and manages a fleet of automated data collection vehicles. The fleet consists of PROFILOGRAPH GE, SKIDDOMETER BV 11, and VIDEO CAR [3] and [4].

\subsection{Pavement structure assessment}

Pavement Structure Assessment is aimed at provision of data regarding residual service life of particular pavement and required

\footnotetext{
* Jan Mikolaj, Frantisek Schlosser, Lubos Remek

Faculty of Civil Engineering, University of Zilina, Slovakia, E-mail: jan.mikolaj@fstav.uniza.sk
} 
overlay thickness. The measurements are performed by dynamic deflectometer FWD KUAB 150 - more details attainable in [5] it is a falling-weight loading system which transfers the impulse to the pavement construction, to create a temporary deflection, which is measured by series of velocity transducer sensors. The deflection bowl is used during calculations of Young's modulus of elasticity of particular layers, residual service life of the pavement and required overlay thickness. The calculation is, for the needs of RNMS, incorporated into software called Comprehensive Analysis of the Pavement Bearing Capacity - CANUV [6].

\subsubsection{Residual service life calculation}

The elastic modulus of asphalt layers recalculated to $11^{\circ} \mathrm{C}$ temperature, and elastic modulus of the sub-base and subgrade, as results from the backcalculation are used in this calculations. The residual life of the pavement is calculated according to two criterions. The first criterion is the cracks initiation at the bottom edge of the bound layers, and the second criterion is load bearing capacity of the subgrade.

Criterion of crack initiation at the bottom edge of the bound layers is considered satisfied, when equation (1) applies.

$$
\frac{\sigma_{r, i}}{S_{N} \times R_{i, j}} \leq 1
$$

$\sigma_{r, i}=$ radial stress on the bottom edge of the bound layer " $\mathrm{i}$ " [MPa];

$R_{i}=$ maximal tensile stress produced at the point of failure after one loading cycle of the pavement layer "i" [MPa];

$S$ = fatigue coefficient of the pavement layer material.

According to design methodology, the fatigue coefficient $S$ is dependent on the number of repetitions of standard axle load (SAL) and it is derived from experimental measurements. It can be expressed as:

$$
S=A-B \cdot \log N
$$

$A, B=$ fatigue coefficients derived for a variety of asphalt and cement-bound materials;

$N=$ residual service life of particular layer expressed in standard axles loads [SAL].

Consequently, after integrating (2) into (1), residual service life of layer i can be calculated according to equation (3).

$$
\log N_{i}=\frac{A \times R_{i}-\sigma_{r, i}}{B \times R_{i}}
$$

$N_{i}=$ residual service life of layer "i” in standard axles load [SAL];

$\sigma_{r, i}=$ calculated radial stress on the bottom edge of the pavement bounded layer "i“ " $[\mathrm{MPa}]$;

$A, B=$ fatigue coefficients derived for a variety of asphalt and cement-bound materials. Their value lies within interval:

A, B for bituminous layers $\quad A=0.95-0.9 \quad B=0.11-0.12$

A, B for cement bounded layers $A=0.90-1.0 \quad B=0.07-0.80$
Analysis of long-term measurements was carried out, based on methodology [7]. The aim of these measurements was to identify residual service life. Provided that those results have not proved significant changes, other methods are used to establish the tendency lines for residual service life.

Due to the fact that the radial stress calculation can be performed by means of a mathematical model - the layered elastic half-space model - and due to the fact that the resiliency of particular layers can be derived from laboratory measurements, the determining factor for the accuracy of residual service life calculation is the fatigue coefficient $S$. In this article, application of fatigue modelling theory is presented and supported with measured values. "Two-point bending test" was used for specification of the fatigue coefficient. This test is performed in accordance with national methodology [8] and current European standard [9]. The basic characteristics include elasticity modulus, deformation modulus, modulus of stiffness creep ratio and Poisson's ratio. Measurement of the complex stiffness modulus is performed at short-term alternating harmonic load. Complex stiffness modulus expresses the proportion of maximum amplitudes of excitation tension and deformation induced by this tension and phase shift of the amplitude. The stress, which varies sinusoidally in time, is applied on the element made of linear viscoelastic material. The strain - deformation - varies in time with the same frequency as the stress, but it lags behind by a phase. For the purpose of PMS, variety of measurements has been made on bitumen bound samples extracted directly from the test track of the CCT facility [10]. Following formulas for fatigue coefficient calculation were derived as results of tests on samples made from modified and unmodified asphalt.

Asphalt concrete $\mathrm{AC} 11$ and $\mathrm{AC} 22$ :

$$
\begin{array}{lll}
\text { AC } 11 \quad S=A-B . \log N & A=1 & B=0.10 \\
\text { range: } 0.078 \text { to } 0.129 & & \\
\text { AC 22 } \quad S=A-B . \log N & A=1 & B=0.06 \\
\text { range: } 0.060 \text { to } 0.125 & &
\end{array}
$$

Stone Mastic asphalt:

$$
\text { SMA } \quad S=A-B \cdot \log N \quad A=1 \quad B=0.08
$$

Ascertained fatigue values are higher than life expectancies of asphalt bound mixtures, which are stated in the design method. In accordance with the European standard [11], fatigue has to be defined by means of linear regression represented by a logarithmic function. This function has to be based on results, which represent the length of service life Ni for relative deformation $\varepsilon_{i}$ chosen through the linear regression between the value of $\lg \mathrm{Ni}$ and value $\lg \varepsilon_{i}$ according to formula (4)

$$
\lg N_{i}=a+\left(\frac{1}{b}\right) \cdot \lg \varepsilon
$$

$N_{i}=$ conventional fatigue life of sample i;

$a=$ ordinate of the function;

$1 / b=$ steepness of the function;

$\lg \varepsilon=$ average value of $\lg \varepsilon_{i}$. 


\begin{tabular}{|c|c|c|c|c|c|c|}
\hline \multirow{2}{*}{ Mixture } & \multicolumn{5}{|c|}{ Fatigue of asphalt mixture $\left(T=+10^{\circ} \mathrm{C} ; F=25 \mathrm{~Hz}\right)$} & \multirow{2}{*}{ Category } \\
\cline { 2 - 6 } & \multicolumn{3}{|c|}{ Fatigue coefficients } & \multicolumn{2}{c|}{ Microstrain } & \\
\cline { 2 - 6 } & $A_{o}$ & $A_{1}$ & $b$ & $\varepsilon_{6}{ }^{*} 10^{-6}$ & $\varepsilon^{*} 10^{-6}$ & \\
\hline $\mathrm{ACo} 11 \mathrm{PmB} 45 / 80-75 ; \mathrm{I}^{11}$ & -13.69 & -4.85 & -0.206 & 87.44 & 117.75 & $\varepsilon_{6}-115$ \\
\hline
\end{tabular}

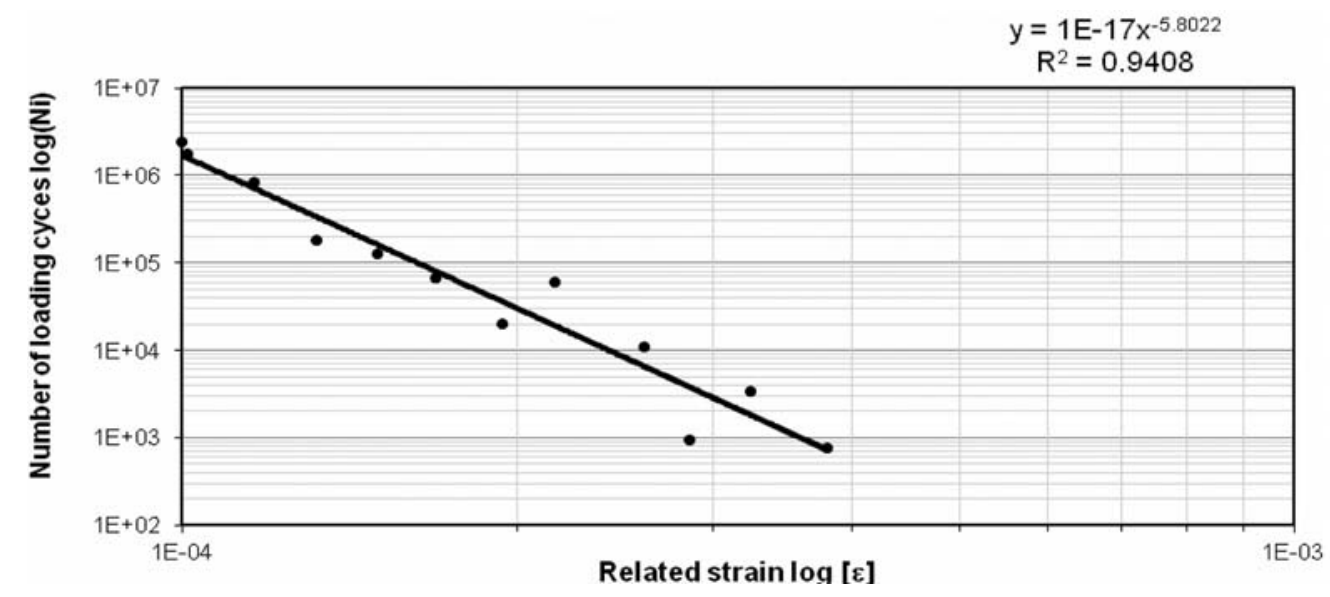

Fig. 1 Wohler diagram for ACo 11 PmB 45/80-75

In terms of fatigue, value of relative deformation $\varepsilon_{6}$ is an arbitrary one. It is derived from linear regression for 1 million of load cycles. As an example, in Fig. 1, we present relationship of the serviceability expressed by number of loading cycles $N_{i}$, to the relative deformation $\left(\varepsilon_{i}\right)$ for asphalt concrete in Table 1.

\section{Benefits gained by MR\&R actions}

Identification and calculation of benefits gained through repaired pavements is a key factor for economic efficiency calculation. Benefits are calculated as a difference in transportation costs before the MR\&R action and decreased transportation costs stemming from improved pavement parameters as a result of the MR\&R action. Benefits may be internal or external. Internal benefits are the road user costs which consist of vehicle operating costs and travel time costs. External benefits are monetized savings from emission reduction, noise emissions and accident rate reduction. Dust emissions and vibration are in the process of implementation into the system. The vehicle operating costs are the transportation costs, which include fuel consumption, lubricant consumption, car maintenance, wearing of tires, and transportation time of cargo and passengers.

\section{Cost benefit analysis}

The calculation of economic efficiency of chosen repairs is based on comparison of the benefits they will produce and their procurement and maintenance costs. In view of the fact that it is necessary to incorporate a huge amount of data from the pavement diagnostics, future maintenance costs, year in which the repair will take place, expected service life of the repair and calculated benefits, an algorithm of this procedure - decision making algorithm was established to incorporate all the relevant data. Diagram of the algorithm is shown in Fig. 2. The procurement costs for particular MR\&R method are included in the library of technologies, which is annually updated with new market prices, paid by the administrator. Following are the economic indicators of CBA: Internal Rate of Return (IRR), Net Present Value (NPV), BenefitCost Ratio (B/C), Payback Period (PP).

\section{Results}

The application of LCCA provides us with fund allocation strategies and creation of site specific plans for MR\&R actions, i.e. plans for meeting the performance objective. The application proved that the resources are allocated to road sections which have the highest demand for repairs, thus financial funds are used effectively. The saved funds are in turn used as additional resources for further repairs. Another important fact is that this systematic approach increased the discipline of subcontractors of repair works, employed by road administrators [12]. The road network administrator has, by means of LCCA, a huge number of results, enabling him to optimize his activities; for example, the trend lines of roughness, skid resistance or surface damage. 


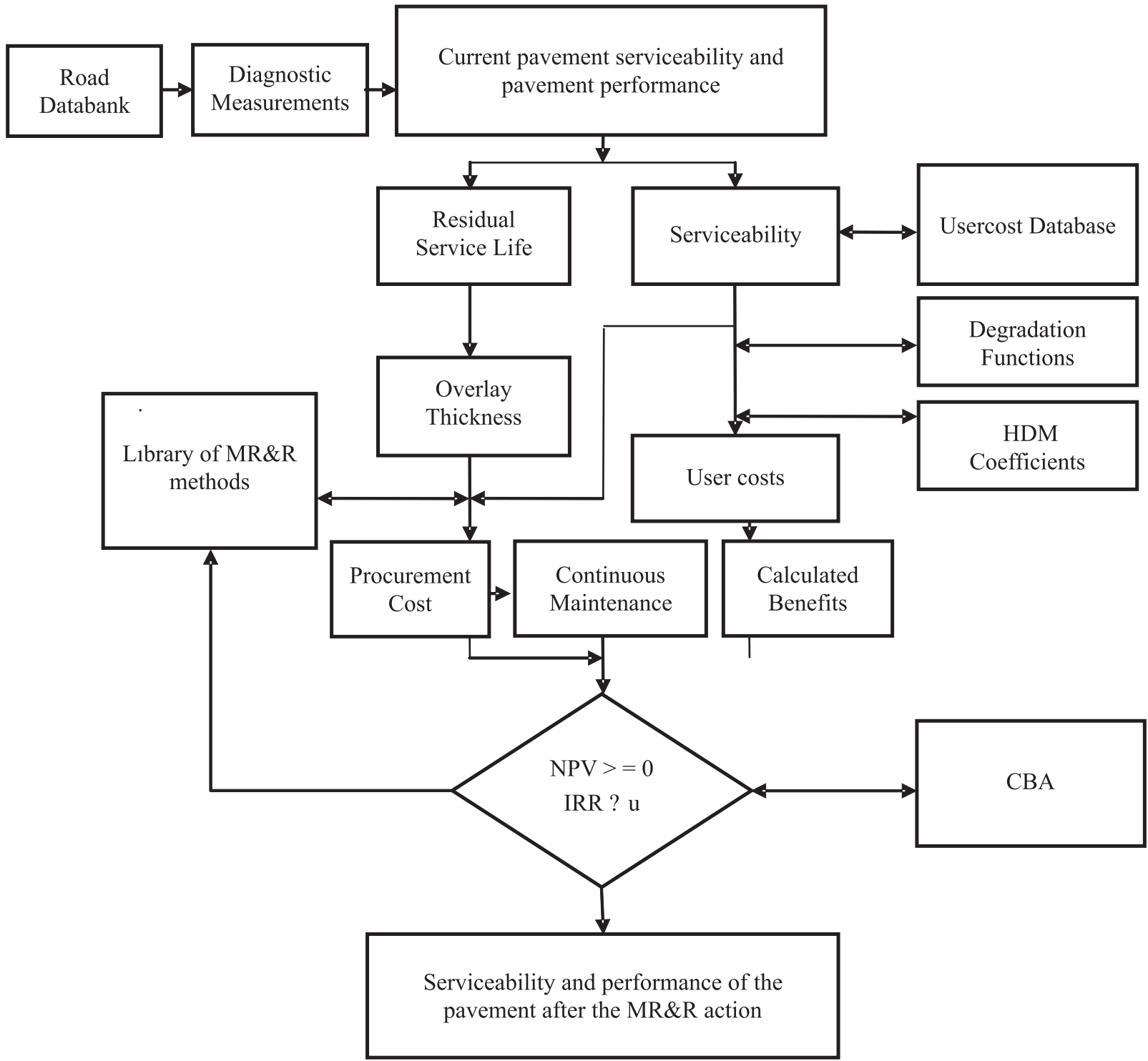

Fig. 2 Algorithm for selection of appropriate MR\&R method

Application of LCCA allows for different variants of financing. As seen in [13], the economic calculations have also enabled us to increase value of money spent for repairs by financing through European Investment Bank loans or Public Private Partnerships between road administrator, construction subcontractor, and a bank.

In further development of the program, it will be necessary to focus on the completion of calculations performed in the CBA in regards to investment into new infrastructure; it will be also necessary to incorporate other factors like environmental impacts - noise, dust, vibration, exhaust emissions. Currently, as seen in [12] and [13], these factors are calculated only outside of the computational program.

\section{Acknowledgement}

This contribution is the result of the project implementation: "Independent Research of Civil Engineering Construction for Increase in Construction Elements Effectiveness" (ITMS: 26220220112) supported by the Research \& Development Operational Programme funded by the ERDF. 


\section{References}

[1] MIKOLAJ, J.: The Road Network Management System in Slovakia. Transport Reviews, Taylor and Francis Ltd. London, vol. 16, No. 4, pp. 313-321, 1996.

[2] FEDERAL HIGHWAY ADMINISTRATION: Life-Cycle Cost Analysis in Pavement Design. U.S. Department of Transportation, Federal Highway Administration. Publication No. FHWA-SA-98-079

[3] BENKO, Z.: Pavement Management Systems Employed by Slovak Road Administration. Proc. of Q-2012 Conference Construction, Financing and Management of Roads and Motorways, University of Zilina, pp. 44-482012, ISBN 978-80-554-0572-8.

[4] CELKO, J., KOVAC, M., DECKY, M.: Analysis of Selected Pavement Serviceability parameters. Communications - Scientific Letters of the University of Zilina, No. 3, 2011, ISSN 1335-4205.

[5] ENGINEERING AND RESEARCH, Inc.: Eri Kuab - Falling Weight Deflectometer, 2013, 〈http:www.erikuab.com>.

[6] KOMACKA, J., CELKO, J.: CANUV - Computer Program for Analysis of the Bearing Capacity on the Deflection Bowl Basis. Studies of University of Transport and Communications in Zilina, vol. 19, pp. 63-70, Zilina, 1996.

[7] KOMACKA, J.: Change of Bearing Capacity Characteristics of Asphalt Pavement Communications - Scientific Letters of the University of Zilina, No. 3, 2011, ISSN 1335-4205.

[8] Slovak Office of Standards SUTN: STN 736160 Evaluation of Asphalt Bituminous Mixtures, 1986

[9] European Standardisation Organisation CEN, EN12697-26: Bituminous Mixtures - Test Methods for hot mix asphalt - part 26: Stiffness

[10] SCHLOSSER, F. et al.: Rheological Characteristics of Asphalt Mixtures Extracted from Circular Test Track: Testing of Bituminous Mixtures, VU report No. 93/SvF/98. University of Zilina, 1998

[11] European Standardisation Organisation CEN, EN12697-24: Bituminous Mixtures - Test Methods for Hot-mix Asphalt - part 24. Resistance to fatigue, 2003

[12] TROJANOVA, M., ZGUTOVA, K., PEPUCHA, L., PITONAK, M.: Inter-laboratory Comparison of Accredited Laboratories in Terms of Benchmarking in Slovakia, Communications - Scientific Letters of the University of Zilina, No. 3a, 2010.

[13] MIKOLAJ, J., VALUCH, M., PEPUCHA, L.: Innovative Road Management Arrangement in Slovakia / Dispositifs Novateurs de Gestion de la Route en Slovaquie, Proc. of XXIV World Road Congress Roads for a better life Mobility, sustainability and development, September 2011, Mexico City, DVD 12s. 